\title{
Investigation of Patience Tendency Levels in Terms of Self-determination, Self-compassion and Personality Features
}

\author{
Ayşe Eliüşük Bülbül”, Coşkun Arslan \\ Department of Education Sciences, Konya Necmettin Erbakan University, Turkey
}

Copyright $(2017$ by authors, all rights reserved. Authors agree that this article remains permanently open access under the terms of the Creative Commons Attribution License 4.0 International License

\begin{abstract}
The main objective of this study was to determine the relationship between self-determination, self-compassion and the five-factor personality traits of university students. Moreover it was aimed to determine whether self-compassion, self-determination and personality traits predict patience levels at a meaningful level. The sample population of this research consisted of a total of 1166 students; 704 female and 462 male students from the Universities of Bartın, Batman, Konya Necmettin Erbakan and Selçuk. The age range of the students was 17-30 and the average age was 20.89. The method used to determine students' patience points was the patience scale, which was developed by Schnitker [43] and adapted to Turkish by researchers Eliükük and Arslan [16]. The Self-Compassion Scale (Deniz, Kesici \& Sümer, [15]), the Adjective Based Personality Test (SDKT) (Bacanl, İlhan \& Arslan, [2]) were used in order to determine the self-compassion scores and the Autonomous Self-Determination Scale (Ersoy \& Güldü, [15]) was used to determine the self-determination scores. As a result of the research, a positive relationship was found between all sub-dimensions of patience and self-compassion. There was a significant relationship between the sub-dimensions of patience and the sub-dimension of self-determination. A positive correlation was found between the sub-dimensions of patience and Agreeableness, Openness to experiences and conscientious and a negative relation with Neuroticism. When self-compassion, self-determination and the five-factor personality traits were evaluated separately and together, it was seen that they can predict all sub-dimensions of patience.
\end{abstract}

Keywords Patience, Self-compassion, Selfdetermination, Personality Features

\section{Introduction}

As Patience is a rather new concept in psychology, so it is very difficult to conceptualize and define it. The most known basic meaning is the tendency of a person to wait calmly in the face of frustration, distress and pain (Schnitker, [43]). According to Blount \& Janicik [4], patience is a reaction to delay; it reflects emotions like calmness, sympathy and empathy. According to McClough, Tsang \& Emmons [32]); patience is defined as a typical tendency "like a patient person"; but it is also seen as a situation at the same time. Patience is expressed as a product that emerges from the interaction between personality and situation.

Schnitker [43] states that patience has affective and behavioral characteristics. Patience involves waiting as being behavioral and calmness as being affective. According to Schnitker \& Emmons [44] patience is the combination of the effect of negative stimulation, such as geting bored by waiting for any object or person, and limitation in a compelling situation. Despite the conceptualization differences, the definitions are completing each other. Patience is considered a situation that occurs in response to various times and conditions. For example we show patience in the face of long-standing discomforts or in ordinary temporal delays such as traffic blockage. Patience is often regarded as a temporal component, but cannot be explained by focusing only on time (like waiting for someone to recover from a disease). It is also considered to be a situation of exigent persons and conditions. In addition patience has cognitive and affective properties. This indicates that patience is not congenital but a later acquired condition (Blount \& Janicik, [4]). The attitude towards a delay or a compelling experience shows individual differences. In this context, it is inevitable for the individual to interpret his / her attitude and values so that the patience of any person can be evaluated. Patience is assessed along with cognitive reactions as well as affective responses. The positive and negative feelings of the past in the face of waiting and compelling circumstances of the individual have an important place in the affective evaluation of patience (Dudley, [16]). Curry Price \& Price [10]; describes the 
definition of the patient person as having the power to wait. Mehriban [33] defines patience as a limited, determined and planned tendency (patient people can cope with difficulties and work over them until they reach the target). Mehriban also defines patience as a personality trait. He also evaluates patience temporally. Mehriban speaks of three types of patience. Short-term patience: often referred to as waiting situations in everyday life. For example; situations like traffic congestion, waiting for the bus or plane and waiting in line at a restaurant. Long-term patience: is defined as the ability of individuals to cope with any compelling experiences. For example; Long-term diseases, financial problems, the attitude of mothers against their newborn babies. Interpersonal patience: is defined as the tolerance of persons against other individuals in their social relations. For example; patience shown against tough bosses, parents, adolescents or students.

Schnitker [43] introduced a definition similar to Mehriban's definition and defined patience in three groups. Mehriban's short-term patience description is the same as Schnitker's definition of patience in everyday life (for example traffic block, wait in line etc.). In a similar way, Mehriban also meets long term patience like Schnitker's definition for patience against the challenges of life. The definition for interpersonal patience is the same in both. Carver, Scheier \& Weintraub [7]'s coping inventory (COPE) states that is closely related to patience. Patient persons show positive attitudes towards problems and these positive attitudes are improving coping with problems.

Patient persons are more optimistic and less anxious than others are. Furthermore, patient individuals are more open to cooperation than impatient individuals are. In terms of patience, it can be said that it has its own character in the moral and political perspective. In philosophy, patience is part of the temperance virtue in Plato's book 'Republic'. Patience is not included in the virtues of Christianity. Patience is a personality trait according to the Bible (Uday \& Mehta, [51]). There is a discussion among moral philosophers whether patience is a value or not: What Kierkegaard says about patience, reflects himself. According to Augustin, patience represents the "friendship of wisdom". According to Pliay, patience is "a big part of justice" and these two philosophers say that patience is different from other values (Hayes, [21]. Rosalind Hursthouse researched about Aristotle's ethics of Nicomachean and claimed that patience was not a virtue, it was a character trait; as a character feature that is necessary to be able to pass life well, happily and successfully (Hursthouse [24]).

Patience also has a religious aspect and is defined as an important value in almost all religions. This multi-dimensional structure of patience, led to its superficial evaluation. It is therefore very difficult to identify it (Schnitker, [45]). The definition of patience as a value in our religion (İslam) is based on the 14th century. The mesnavi is created in the 14th century and has many educational elements and value systems under the influence of the values that the era possesses. According to Cebecioğlu [8] the turkish proverb "patience is painful, bu its fruit is sweet" points out that at the end of patience everything will be better but however, it is necessary to draw some distress for it. İn the Mesnavi, the patience value is reflected in the following words: "Patience is salutation." :not complain about problems, recommend patience, be patient with was comes from Allah, know that conquest only can be won with patience, 'the patience dervish came to fruition", Hz. Eyüp is mentioned with his patience, patience for soul problems, "Take the bitter with the sweet.", to tolerate diseases, to believe that patience is a hard virtue, to understand that love makes patience easier. Patience, which means folding, endurance, self-judge, is the endurance of the person against the sufferings and troubles (Çelik, 1998).

Self-compassion is defined for persons which are are open, sensitive, courteous and compassionate towards their sufferings and pains and do not criticize the failures of other individuals (Neff, [35]). Self-compassion helps to restructure and develop cognition (Gilbert, [19]). Self-compassion is a talent; to be kind and self-respecting rather than angry and critical. Individuals can cope better with problems they encounter in various parts of their lives in a more stress-free manner with the help of self-compassion (Neff, [35]). With self-compassion, individuals form an alternative cognition and can see into a logical way. They develop an alternative cognition by interpreting that they feel their experience as supportive and helpful, not as they feel emotionally secure (Gilbert, [19] ). It is a method that helps to reduce stress in thoughts, feelings and behavior through the techniques it comprises (Goss \& Gilbert, [20]). Problems, disstress and agony in self-compassion are considered as common experiences of society (Neff, [34]). There is a close relationship between patience and self-compassion. The concept of patience is one of the basic attitudes of conscious awareness therapies, as it constitutes the foundations of Buddhist philosophy. Patience is a kind of wisdom according to Buddhist philosophy. Patience is to acknowledge and understand that everything has a course of time (Kabat \& Zinn, [26] ). Patience can be improved by raising conscious awareness. Conscious awareness exercises; creative thinking, memory and curiosity do increase patience. Conscious awareness has become a popular concept in recent times. Some publications about this subject are: Thera, [50] (1962); Kabat-Zinn, ([27]; [28]); Hofmann \& Asmundson, [22]; Hofmann, Sawyer, Witt \& Oh, [23]; Roemer \& Orsillo, [38]; Siegel, [48] . Patience and modesty are needed in awareness therapies, formal practices and meditation. Instead of consciously recognizing destructive habits, it is aimed to change them simply with new habits and increase consciousness; but this takes time.

Personality traits, which are another variable in our research, appear to be an important predictor of patience. First, it will be appropriate to define personality. The term personality comes from the Latin "persona" root. The word persona means mask in Latin language. It is a word derived 
from the term 'person' from English, German and Spanish. Personality is also defined as the mask of our behavior or the mask of our feelings and thoughts. The term personality is used in English in several ways, but has generally similar characteristics (Jung, [25]). Many different sources of personality have different definitions; as a result of the studies aimed at defining the concept of personality, researchers have not reached consensus on one single definition. The reason for this was basic sciences and the approach for this subject from different point of views. According to Freud [18]; "Personality is the result of the struggle between id, ego and super ego. It contains both congenital and subsequent structures." According to Rogers [39]; "Personality is an entity that is at the center of each person's subjective, organized, perceived subjective experiences." Allport [1] defined personality as the dynamic organization of the individual in the psycho-physical system that determines the person's adaptation to the environment. Fransic Galton tried to create a classification (taxonomy) that would encompass the personality structure based on the hypothesis that the individual differences exhibited by humans would be coded in all languages in the world and reflected in words. For this reason, psychologists interested in the subject since the 1920s have turned to this rich source for distinguishing the phenotypic personality traits of persons (Somer, [49])

This model defines five new personality traits and includes the taxonomy of the big five. The Five Factor Theory is an international theory. The five dimensions are: Neuroticism, Extraversion, Openness, Compatibility and Conscientious and the term OCEAN consists of the combination of the letters in English. Neuroticism Dimension: the neuroticism dimension, places people at a point on the continuity of emotional stability and personal harmony. Extraversion Dimension: Outward persons are quite social; at the same time, they are energetic, optimistic, warm-hearted and enterprising. Those who behave in the opposite direction are regarded as inwardly oriented. Openness Dimension: means being open to different experiences. Among the features that make up this dimension are strong imagination, desire to accept new views, multifaceted thinking and mental curiosity. Compatibility Dimension: to be helpful, trustworthy and compassionate are involved in this area. Conscientious Dimension: The people at the higher end of this dimension are regular, committed people moving in the direction of the plan. Those on the lower end are careless, distracted and unreliable persons (Burger, [6]). In Schnitker \& Emmons [44] study on patience and five-factor personality theory, a high positive correlation where found between patience and compatibility, conscientious, extroversion and a low negative one for Neuroticism.

When the correlations between the various factors of the patience and the characteristics of the five-person personality were examined, 20 relationships were determined. There was a moderate positive correlation between long-term and short-term patience and compatibility. There was a strong positive correlation between interpersonal patience and compatibility. There is a negative relationship between conscientiousand Neuroticism 3 factors. There was a modest correlation between interpersonal patience and openness for experiences and a small relationship between long-term and short-term patience and openness for experiences. Finally, the relationship between Extraversion and patience types was not statistically significant (Schnitker, [43]).

From these results, it can be said that patient individuals are compatible, responsible and open for different experiences. They may or may not be open to the outside in negative emotions.Looking at the regression between the big five and the three-factor patience; it seems that patience is an important determinant of the big five. There was found a moderate level of negative correlation between compatibility and Neuroticism, high levels of correlation in the positive direction between conscientious and openness to experiences (Schnitker \& Emmons, [44]).

The first studies began in the 1970s with Edward Deci. The most prominent representatives of the theory are Edward Deci and Richard Ryan. Within the framework of the theory, four mini theories were developed over the past 30 years. Each theory was supported by laboratory and field works done on different topics. These theories are briefly explained below (Deci \& Ryan, [11]).

The requirements in the self-determination theory are defined as innate psychological needs (Deci \& Ryan, [14]). The basic psychological needs mentioned in the self-determination theory are necessary for personal growth, integration and subjective well-being (Ryan \& Brown, [40]). The need is also necessary for survival, development and health (Kasser \& Ryan, [29]). The diversity of satisfaction in needs is important for one's self-motivation, adaptation and integration (Deci \& Ryan, [14]).

Psychological needs can be classified as follows. Autonomy: Autonomy is a characteristic acquired in Erikson's psychosocial development theory in the second period. While the child needs to be autonomous on the one hand, there are feelings of guilt and suspicion on the other hand. It is important that the people around him don't let him feel guilty and ashamed. In this period, if the people around, behave in a way that supports the autonomy of the child, it will be a safe autonomy without feelings of suspicion and shame (Ericson, [17]). Efficiency: There are two important points in the concept of efficiency; the first is that a person has the power to do a task and the other is that this person has the belief to do the task (Deci \& Ryan [14]). To be associated: an individual is inherently in the sense of being involved in a group. Every person needs to be in social interaction and this need is mentioned as a necessity for the mental health of the person. The person has to feel that it is communicating with his or her family, close circle, a group or community and wants to establish relationships (Ryan \& Deci, [41]). To be associated means that the individual is related to other important people in his / her life and lives by feeling 
belonging to his / her social environment (Kowal \& Fortier, [30] ). Motivation: can be defined as the power that moves the person towards his/her needs. If the person directs behaviors with this/her own desires and needs, it's called intrinsic motivation; if its the request of others or if its directed by pressure, is referred to external motivation (Deci \& Ryan, [11]). Internal and external motivation will be explained later in detail.

Internal Motivation Internal Motivation; is a tendency to assimilate, to be a judge, to provide sincere interest, research, discovery and personal pleasure (Ryan, [42]). External Motivation Another type of motivation that is less effective than internal motivation in self-determination theory is external motivation. Although it is less effective, it plays an important role in shaping the behavior of the individual. Exterior motivation includes qualities such as avoidance from punishment and draw close to a reward. External motivation can be described as a form of bail payment (Noels, Pelletier, Clément \& Vallerand, [36] ). Amotivation: another definition made by Deci \& Ryan [12]. İf persons do not see any relationship between their individual behaviors and the outcome of their behaviors, or if they do not have any motivation source to internalize or externalize their behavior, it can be called amotivation (Poulsen, Rodger, Ziviani \& Jenny, [37]).

The concept of self-regulation for patience is seen in tolerance situations. It occurs in situations such as the use of standards and social perceptions of individuals in their goals. Distraction in tolerance situations focuses on important and not to be missed hints. For example; rather than focusing on what the speaker is saying during a conversation, the individual is focused on when he will be reminded of when the next staff meeting will be (Blount, [3]). The choices the individual makes; are determined not by external power, pressure and rewards but by the individual's own behavior (Deci \& Ryan, [11]). Self-determination; is defined as that the behavior is not only determined by society norms, group pressure, etc., its rather determined of one's own personal beliefs and value judgments; giving its decisions on its own (Deci \& Ryan, [12]. The Self-Determination Theory explains the difference between a person's freedom of action or the need to do it because he feels compelled or forced (Krapp, [31]). The creativity of self-determination experiences have positive effects about conceptual learning, emotional state and self-esteem (Deci, Connell \& Ryan, [13]. When individuals act with their free will, their behavior will be a result of personal freedom and autonomy (Whetten \& Cameron, [52] ). Looking at the relationship between patience and self-determination, Blount \& Janicik [4] are mentioning three mechanisms in understanding patience behavior: frustration-regression, self-regulation and temporal sacrifice. When individuals feel impatience, they avoid being blocked to avoid a negative outcome. They prepare themselves to wait, try to reduce cognitive barriers. They can show individual impatience after a negative experience. The individual will try to avoid waiting or being prevented by cognitive techniques. In case of cognitive restructuring, individuals prepare themselves mentally (For example, when there is a delay "sometimes I may have to wait"). İ situations such as calm themselves down and self-restraint with emotional coping strategies, it was seen that the impatience of individuals were reduced. In addition, in distracting situations such as, books, knitting or paperwork, blocking will be experienced less. Temporal sacrifice gives priority to the realization of the goals of others with the deferment of their own goals. Scnitker \& Emmons [44] seperated patience from self-determination. They claimed that patience is a part of self-regulation. İn the model of Blount \& Janicik [4] is patience not just a simple attitude in conscientious and evaluation. Patience also has cognitive and behavioral bases. Patient persons are calmer and compassionate, impatient persons are accusatory and nervous. Patient people can also perform a cognitive and behavioral self-regulation. Alternatively, they can easily evaluate and assess the problem situation.

In the studies conducted it was seen that patience was related wit variables like physical health, well-being, subjective well-being, positive coping, development of values and values, personality and the social processes in the background of personality and that patience is an important predictor of these variables. It has also been observed that patience increases the quality of life. In this study the effects of patience on self-compassion, self-determination and personality characteristics were examined. İts an important point that the patience scale adapted to Turkish in this process will be used the first time in a study.

Personality traits, which are one of the independent variables of this research, are mainly formed because of interaction between heredity and environment. These days, the five-factor personality model represents the common validity of personality research and its universal language. Considering the theoretical basis of the five-factor personality traits, it can have an important effect on the patience levels of individuals. This research is also important in determining the relationship between five-factor personality traits and patience. In addition, this study, in which the effect of patience over self-determination, self-understanding and five-factor personality traits are examined, is also important because it is the first study in our country. It is also expected that this study will give some light to the researches that will be made in our country in the future.

\section{Materials and Methods}

Model of the study: This research was in the relational screening model. Research data were collected for the purpose of determining whether self-compassion, self-determination, and five-factor personality traits can significantly predict patience levels in university students, if there was a significant relationship between patience and self-compassion, self-determination, and five-factor 
personality traits and whether the patience scores of the university students differed with personal characteristics (gender and age) or not.

Population and Sample: The population of this research were the students who are studying at Bartın University, Batman University, Konya Necmettin Erbakan and Konya Selçuk University. The working sample of the study were Konya Necmettin Erbakan University (Ahmet Keleşoğlu Education Faculty, Faculty of Science and Literature), Bartın University (Faculty of Education, Faculty of Forestry, Faculty of Economics and Administrative Sciences), Batman University (Vocational High School, Faculty of Science and Literature, Faculty of Engineering). The sample of the study were students of the 1.2.3. and 4 class in various parts of these faculties and were selected by random cluster sampling method.

The research sample consisted of a total of 1166 students, 704 female and 462 male. The age range of the students were 17-30 with an average of 20.89. The distribution of the sample of students according to various variables is given in Table 1.

\subsection{Data Collection Tools}

In addition to the personal information form, the following scales were used to collect research data. Measuring instruments used:

Patience scale (Schnitker and Emmons, [44]): The patience scale developed by Schnitker and Emmons [44] was undergone an adaptation study by Eliüşük, Arslan16] . The patience scale was used to self-evaluate beliefs about the importance of the patience behavior. There are three sub-dimensions on the scale; interpersonal, long-term and short-term. There are in total 11 items on the scale. İtems 1. 4. 7. 9.11. are measuring interpersonal patience, items 2. 5. 5. 8. measure long-term patience (for life difficulties), items 3. 6 . 10. are measuring short-term patience (everyday troubles) in the seven point likert scale $(1=$ completely not like me and 7 $=$ completely like me). The internal consistency coefficient was .80. The patience scale had a meaningful positive relationship with all dimensions of the five major personality models, attachment, awareness and subjective well-being.

Table 1. Distribution of the Sample of Students According to Faculty, Gender and Age Variables

\begin{tabular}{|c|c|c|c|c|}
\hline & Gender & Age between 15-19 & Age over 20 & Total \\
\hline \multirow{2}{*}{ Bartın Education Faculty } & Female & 71 & 42 & 104 \\
\hline & Male & 33 & 38 & 80 \\
\hline \multirow{2}{*}{ Bartın Faculty of Forestry } & Female & 29 & 7 & 54 \\
\hline & Male & 25 & 12 & 19 \\
\hline \multirow{2}{*}{ Bartın Faculty of Economics and Administrative Sciences } & Female & 100 & 58 & 128 \\
\hline & Male & 27 & 39 & 97 \\
\hline \multirow{2}{*}{ Konya Necmettin Erbakan University Faculty of Education } & Female & 89 & 48 & 141 \\
\hline & Male & 51 & 37 & 85 \\
\hline \multirow{2}{*}{ Selçuk University Vocational Education Faculty } & Female & 53 & 32 & 73 \\
\hline & Male & 20 & 25 & 57 \\
\hline \multirow{2}{*}{ Selçuk University Faculty of Social and Human Sciences } & Female & 37 & 22 & 56 \\
\hline & Male & 18 & 21 & 43 \\
\hline \multirow{2}{*}{ Batman Vocational School } & Female & 16 & 4 & 43 \\
\hline & Male & 27 & 7 & 11 \\
\hline \multirow{2}{*}{ Batman Science and Literature Faculty } & Female & 65 & 31 & 75 \\
\hline & Male & 10 & 19 & 50 \\
\hline \multirow{2}{*}{ Batman Engineering Faculty } & Female & 19 & 12 & 30 \\
\hline & Male & 11 & 8 & 20 \\
\hline
\end{tabular}


An adaptation study was carried out on a group of university students with the patience scale. İn order to test the language validity of the scale; there were found significant positive correlations $(\mathrm{r}=.95, \mathrm{p}<.01 ; \mathrm{r}=.95, \mathrm{p}<.001)$ between the scores obtained from the English and Turkish forms that were translated opposing (English-Turkish; Turkish-English) from students of the department of English teaching. A confirmatory factor analysis was used to determine factor structures of the patience scale. It has been verified that the scale is three-dimensional according to the results of the confirmatory factor analysis. In the total correlation of the items made of the patience scale, all the items of the scale were in the relationship above .40. The item factor loads for each item of the patience scale ranged from .50 to .84 . The Cronbach Alpha internal consistency coefficient of the scale was calculated as .82 and the test retest correlation was calculated as .81 . As a result of the correlation analyses made for the criterion validity of the patience scale; the students' scores on the patience scale were found to be positively related to self-recovery, social self-efficacy, sub-dimension of interpersonal problem solving and sub-dimension of the tenacious approach.

Self-Compassion Scale (Deniz, Kesici \& Sümer, [15]): Self Compassion Scale (SCS) consists of 6 subscales with 26 items. The persons were asked to rate how often they move about the situation indicated by the respondents in the scale, on a 5-point Likert-type scale ranging from "almost never = $1 "$ to "almost always $=5 "$. The SCS was developed by Neff [35] and its Turkish reliability and validity study was done by Deniz, Kesici \& Sümer [15]. The difference of the Turkish Self-compassion Scale (ÖAÖ) from the original one is that it has a one-dimensional structure and a total of 24 items were obtained by subtracting 2 items from the scale that had a correlation under .30. Furthermore, the internal consistency coefficient was calculated as .89 and test-retest correlation was calculated as .83 . The criterion-related validity of the self-compassion scale was; between SCS and RSES $\mathrm{r}=.62$; between SWLS $\mathrm{r}=.45$; between positive emotions $\mathrm{r}=.41$ and between negative emotions $\mathrm{r}=-.48$ relationships were found.

Adjective-Based Personality Test (SDKT) (Bacanl, Ilhan \& Arslan, [2]).:The Adjective-Based Personality Test was developed by Bacanlı \& İlhan and Arslan [2]. The SDKT consists of five sub-dimensions (Neuroticism, extroversion, openness to experience, empathy, conscientious). In order to test the structure validity of the SDKT, Principal Components Factor Analysis was performed on the data obtained from 285 participants. As a result of the analysis, five factors revealed $52.63 \%$ of the variance belonging to SDKT. Sociotropy Scale, Conflict Response Scale, Negative-Positive Feeling Scale, Continous Anxiety Inventory were used to test the concordance validity of the SDKT. When examined in general, it has been found that the dimensions of SDKT are moderate and meaningful with the scales used for concordance validity, and that these results are important in terms of concordance validity. Within the reliability studies of SDKT, the internal consistency coefficients of the instrument were calculated on the data obtained from 285 participants and SDKT was applied to 90 participants with an interval of two weeks. The internal consistency coefficients of the dimensions of SDKT were found to vary between .73 and .89 . When the findings related to the SDT test repetition were examined, it was found that the highest associations were the Agreeableness $\left(\mathrm{r}=.86^{* *}, \mathrm{p}\right.$ $<.01)$ and the lowest relationship was the Openness to Experience dimension $\left(\mathrm{r}=.68^{* *}, \mathrm{p}<.01\right)$.

\subsection{Self-Determination Scale (Ersoy K. \& Güldü, [15]}

The Self-Determination Scale was developed by Sheldon \& Deci [46] to assess individual differences in autonomous decision-making. The Self-Determination Scale was adapted to Turkish by Ersoy K. \& Güldü [16] . The scale consists of 10 items and has two factors; "self-contact" and "choicefulness". Participants were asked to determine the most accurate appearance according to them from the expression pairs given on the scale. For example, against the expression "My feelings sometimes seem strange to me", was the expression "I always think that my feelings belong to me" and this was symbolizing "Self-contact"; The expression "what I do is mostly not what I choose" was against the expression "I'm free to do everything what I choose to do" and this symbolized the "choicefulness" condition. Participants made this determination based on a nine-point Likert-type scale ranging from "only the expression A is completely true" to "only the expression B is completely true". After the evaluation, both total autonomous decision points and the scores of the two sub dimensions could be obtained. In many of the examples that have been applied to the scale's adaptation study, the alpha values which are. 85 -.93 , indicated that the scale had a good internal reliability. The test-retest reliability were found .77 when applied with an 8-week interval. This scale also found a strong relationship between psychological health measures that included self-actualization, empathy and life satisfaction, and creativity, resistance to peer pressure, and autonomy (Sheldon, Ryan, Deci \& Kasser, [47]). However, in the trial application before the adaptation study, it was seen that the nine-step response form was not suitable for the Turkish language, the participants' judgments were difficult to determine the midpoint of grading and most of them left unanswered.

\section{Conclusions}

\subsection{Data Collection and Analysis}

In order to collect the research data, the sample group, which was randomly determined beforehand, was informed 
earlier about the time the scale will be applied. The "Patient Scale", "Self-Compassion Scale", "Adjective Based Personality Test (SDKT)", "Autonomous Self-Management Scale" and Personal Information Form were applied at the agreed times. Before applying, the guidelines about the scales were read, information about the application was given, and questions from students about the application were answered. The applications lasted approximately 35-40 minutes. No problems were encountered during the application.

\subsection{Analysis of Data}

At first stage, the scales were numbered separately. In the first study, 44 students who filled in the scale wrong or incomplete, where excluded from the sample. The independent variables of this study consisted of self-compassion, five-factor personality traits, self-determination, gender and age. The dependent variable of the study was the tendency to be patient. The scores obtained from the four scales and other independent variables were entered into a computer by coding. After the coding process, the SPSS 16.0 package program was used to analyze the data. The significance test fort the difference between the mean of the groups according to the gender and age variables of the patience point averages, were made by the $t$ test. For analyzing the relationship between patience, self-compassion, five-factor personality traits and self-determination, The Pearson Moments Multiplication Correlation Coefficient technique was utilized. Whether self-compassion, self-determination, and five-factor personality traits predict patience significantly, was calculated by multiple regression and stepwise regression analysis.

\subsection{Findings}

The Pearson Moments Correlation technique was used to determine whether there was a meaningful relationship between the patience scores and self-determination scores of university students, and the results are shown in Table 2.
Table 2. The Relationship between Patience in Daily Life Points and Self-Determination Points of Students

\begin{tabular}{|c|c|c|c|}
\hline \multicolumn{2}{|c|}{} & $\begin{array}{c}\text { Individual } \\
\text { Awareness }\end{array}$ & Choicefulness \\
\hline $\begin{array}{c}\text { Patience in everyday } \\
\text { life }\end{array}$ & $\mathrm{r}$ & $.15^{* *}$ & $-.02^{*}$ \\
\cline { 2 - 4 } & $\mathrm{P}$ & $.00^{* *}$ & $.36^{*}$ \\
\hline $\begin{array}{c}\text { Patience in life } \\
\text { difficulties }\end{array}$ & $\mathrm{r}$ & $.12^{* *}$ & $.02^{*}$ \\
\cline { 2 - 4 } & $\mathrm{P}$ & $.00^{* *}$ & $.45^{*}$ \\
\hline \multirow{2}{*}{\begin{tabular}{c} 
Interpersonal patience \\
\cline { 2 - 4 }
\end{tabular}} & $\mathrm{r}$ & $.18^{* *}$ & $.02^{*}$ \\
\cline { 2 - 4 } & $\mathrm{P}$ & $.00^{* *}$ & $.45^{*}$ \\
\hline
\end{tabular}

**p $<.01, * \mathrm{p}<.05$,

As seen in Table 2, there was a significant positive relationship between the students' patience in daily life scores and Self-contact scores $(r=.15, p<001)$, there was no significant relationship between the choicefulness scores $(\mathrm{R}=.029, \mathrm{p}>001)$. There was a significant positive correlation between patience scores and Self-contact $(r$ $=.12, \mathrm{p}<.001)$ and choicefulness $(\mathrm{r}=.02, \mathrm{p}>.001)$ scores in life difficulties. Finally, there was a positive correlation between the interpersonal patience scores of the university students and the conscious awareness scores $(\mathrm{r}=.18, \mathrm{p}$ $<001)$ and the choicefulness scores $(r=.13, p>001)$ as the sub-scale of self-determination.

The Pearson Moments Correlation technique was used to determine whether there was a meaningful correlation between the patience scores of the university students and the five factor personality traits subscales and the results are given in Table 3.

As seen in Table 3 there was found a positive relation between the students' patience scores in daily life and Openness $(\mathrm{r}=.064 \mathrm{p}<005)$, Agreeableness $(\mathrm{r}=.228, \mathrm{p}$ $<001)$ and conscientious $(r=.185, p<001)$ and Neuroticism

$(\mathrm{r}=.185, \mathrm{p}<=-.433, \mathrm{p}<001)$ was found to be negatively significant. There were no significant correlation with the Extraversion scores $(\mathrm{R}=.020, \mathrm{p}>005)$. The relation between patience in life difficulties and Extraversion $(\mathrm{r}=.091, \mathrm{p}<005)$ Openess $(\mathrm{r}=.125, \mathrm{p}<001)$, Agreeableness $(r=.243, p<001)$, conscientious $(r=.230, p<001)$ was in a positive direction and Neuroticism $(\mathrm{r}=-.360, \mathrm{p}<001)$ negatively significant. The relation between interpersonal patience and Extraversion $(\mathrm{r}=.049, \mathrm{p}>001)$ Openness $(\mathrm{r}=.028, \mathrm{p}>001)$, Agreeableness $(\mathrm{r}=.228, \mathrm{p}<001)$ and conscientious $(\mathrm{r}=.090, \mathrm{p}<005)$ was in a positive direction and Neuroticism $(\mathrm{r}=-.272, \mathrm{p}<001)$ negatively significant.

Table 3. Relationship between Patience in Daily Life Points and Self-Determination Points of Students

\begin{tabular}{|c|c|c|c|c|c|c|}
\hline & & Neuroticism & Extraversion & Openness & Agreeableness & conscientious \\
\hline \multirow{2}{*}{ Patience in daily life } & $\mathrm{r}$ & $-.43^{* *}$ & .02 & $.06^{*}$ & $.23^{* *}$ & $.18^{* *}$ \\
\cline { 2 - 7 } & $\mathrm{P}$ & $.00^{* *}$ & .52 & $.04^{*}$ & $.00^{* *}$ & $.00^{* *}$ \\
\hline $\begin{array}{c}\text { Patience in life } \\
\text { difficulties }\end{array}$ & $\mathrm{r}$ & $-.36^{* *}$ & $.09^{* *}$ & $.12^{* *}$ & $.24^{* *}$ & $.23^{* *}$ \\
\cline { 2 - 7 } & $\mathrm{P}$ & $.00^{* *}$ & $.00^{* *}$ & $.00^{* *}$ & $.00^{* *}$ & $.00^{* *}$ \\
\hline $\begin{array}{c}\text { İnterpersonal } \\
\text { patience }\end{array}$ & $\mathrm{r}$ & $-.27^{* *}$ & .05 & .03 & $.23^{* *}$ & $.09^{* *}$ \\
\cline { 2 - 7 } & $\mathrm{P}$ & $.00^{* *}$ & .10 & .36 & $.00^{* *}$ & $.00^{* *}$ \\
\hline
\end{tabular}

**p $<.01, * \mathrm{p} \ll .05$ 
The Pearson Moments Correlation Correlation technique was used to determine whether there was a meaningful relationship between the patience in everyday life scores and the self-compassion scores of the university students, and the results are given in Table 4.

Table 4. Relationship between Patience in Daily Life Points and Self-compassion Points of Students

\begin{tabular}{|c|c|c|}
\hline & & Self-compassion \\
\hline \multirow{2}{*}{ Patience in daily life } & $\mathrm{r}$ & $.32^{* *}$ \\
\cline { 2 - 3 } & $\mathrm{p}$ & $.00^{* *}$ \\
\hline \multirow{2}{*}{ Patience in life difficulties } & $\mathrm{r}$ & $.33^{* *}$ \\
\cline { 2 - 3 } & $\mathrm{P}$ & $.00^{* *}$ \\
\hline \multirow{2}{*}{ İnterpersonal patience } & $\mathrm{r}$ & $.24^{* *}$ \\
\cline { 2 - 3 } & $\mathrm{P}$ & $.00^{* *}$ \\
\hline
\end{tabular}

** $p<.01, *$ * $\prec .05$,

As seen in table 4 there was found a positively significant relation between the students Patience in daily life scores and self- compassion scores $(\mathrm{r}=-.324, \mathrm{p}<001)$, Patience in life difficulties $(\mathrm{r}=.330, \mathrm{p}<001)$ and İnterpersonal patience $(\mathrm{r}=.243, \mathrm{p}<001)$

The results of the analysis of whether self-determination, self-compassion and the five-factor personality traits predict patience in everyday life significantly are presented in Table 5 .

In Table 5 results of multiple regression analysis of self-determination, self-compassion and personality traits in everyday life are given. When examined if self-determination predict patient in daily life, it is seen that the self-determining alone explains $4 \%$ of patience in everyday life and is an important predictor of patience in everyday life $\left(\mathrm{R}=21, \Delta \mathrm{R}^{2}=.05, \mathrm{~F}=18.321, \mathrm{p}<001\right)$. In the second step of the model, it is seen that self-determination and self-compassion are also meaningful contributors to the model; self-determination and self-compassion together explain $14 \%$ of patience in everyday life. In the third step of the model it is seen that self-determination and self-compassion together with five factor personality traits were found to have a meaningful contribution to the model; self-determination, self-compassion and personality traits together explain $28 \%$ of the patience in everyday life. Neuroticism $(\beta=-.35, \mathrm{p}<.001)$, Agreeableness $(\beta=.14$, $\mathrm{p}<.001)$ and Conscientious $(\beta=.-12, \mathrm{p}<.005)$ where found to be the best predictors for patience in everyday life.

The results of the analysis of whether self-determination, self-compassion and five factor personality traits do predict patience for difficulties in life are presented in Table 6.

Table 5. Findings of whether Self-Determination, Self-Compassion, and Five-Factor Personality Traits predict Patience in Everyday Life of Students

\begin{tabular}{|c|c|c|c|c|c|c|c|c|c|}
\hline Mode & & $\mathrm{R}$ & $\mathrm{R}^{2}$ & $\Delta \mathrm{R}^{2}$ & $\mathrm{~F}$ & Df & Beta & $\beta$ & $\mathrm{P}$ \\
\hline & Stable & & & & & & & 14.91 & .00 \\
\hline \multirow[t]{3}{*}{1} & Self-contact & $.21 \mathrm{a}$ & .05 & .04 & 18.321 & $2 / 1163$ & .19 & .16 & $.00 * *$ \\
\hline & Choicefulness & & & & & & -.04 & -.05 & .26 \\
\hline & Stable & & & & & & & 8.0 & $.00 * *$ \\
\hline \multirow[t]{2}{*}{2} & Self-compassion & $.37 \mathrm{~b}$ & .14 & .14 & 41.291 & & .33 & .09 & $.00 * *$ \\
\hline & Stable & & & & & & & 12.80 & \\
\hline \multirow[t]{5}{*}{3} & Neuroticism & $.53 \mathrm{c}$ & .29 & .28 & 38.062 & $7 / 1158$ & -.35 & -.19 & $.00 * *$ \\
\hline & Extraversion & & & & & & -.05 & -.02 & .27 \\
\hline & Openness & & & & & & -.06 & -.04 & .14 \\
\hline & Agreeableness & & & & & & .14 & .06 & $.00 * *$ \\
\hline & Conscientious & & & & & & .12 & .07 & $.00 * *$ \\
\hline
\end{tabular}

$* * \mathrm{p}<.01, * \mathrm{p}<.05$,

Table 6. Findings of whether Self-Determination, Self-Compassion and Five-Factor Personality Traits Predict Patience in Life Difficulties in Students

\begin{tabular}{|c|c|c|c|c|c|c|c|c|c|}
\hline Mode & & $\mathrm{R}$ & $\mathrm{R}^{2}$ & $\Delta \mathrm{R}^{2}$ & $\mathrm{~F}$ & Df & Beta & $\mathrm{B}$ & $\mathrm{P}$ \\
\hline & Stable & & & & & & & 9.19 & .00 \\
\hline \multirow[t]{3}{*}{1} & Self-contact & $.17 \mathrm{a}$ & .03 & .02 & 11.007 & $2 / 1163$ & .16 & .09 & $.00 * *$ \\
\hline & Choicefulness & & & & & & -.02 & -.02 & .54 \\
\hline & Stable & & & & & & & & 4.14 \\
\hline \multirow[t]{2}{*}{2} & Self-compassion & $.38 b$ & .14 & .14 & 43.003 & $3 / 1162$ & .36 & .06 & $.00 * *$ \\
\hline & Stable & & & & & & & & 4.70 \\
\hline \multirow[t]{5}{*}{3} & Neuroticism & $.50 \mathrm{c}$ & .25 & .24 & 32.576 & $7 / 1158$ & -.24 & -.09 & $.00 * *$ \\
\hline & Extraversion & & & & & & -.08 & -.02 & $.05 *$ \\
\hline & Openess & & & & & & .00 & .00 & .95 \\
\hline & Agreeableness & & & & & & .10 & .03 & $.00 * *$ \\
\hline & Conscientious & & & & & &, 21 & .08 & $.00 * *$ \\
\hline
\end{tabular}

$* * \mathrm{p}<.01, * \mathrm{p} \prec .05$, 
When Table 6 is examined, results of multiple regression analysis are given of whether self-determination, self-compassion, and personality traits do predict patience in life difficulties. When examined if self-determination predict patience in life difficulties, it was seen that self-determination alone revealed $2 \%$ of patience in life difficulties and was found to be an important predictor of patience in life difficulties $\left(\mathrm{R}=17, \Delta \mathrm{R}^{2}=.03, \mathrm{~F}=18.321, \mathrm{p}\right.$ $<001)$. In the second step of the model, it is seen that self-determination and self-compassion are also meaningful contributions to the model, self-determination and self-compassion together explain $14 \%$ of patience in life difficulties. In the third step of the model, it is seen that self-determination and self-compassion together with five factor personality traits were found to have a meaningful contribution to the model; self-determination, self-compassion and personality traits together explain $24 \%$ of the patience in life difficulties. Neuroticism $(\beta=-.24$, p $<.001)$, Agreeableness $(\beta=.10, \mathrm{p}<.005)$ and conscientious $(\beta=.-21, p<.005)$ where found to be the best predictors for patience in life difficulties.

When Table 7 is examined, results of multiple regression analysis are given of whether self-determination, self-compassion, and personality traits do predict interpersonal patience. When examined if self-determination predict interpersonal patience, it was seen that self-determination alone revealed $2 \%$ of interpersonal patience and was found to be an important predictor of interpersonal patience $\left(\mathrm{R}=14, \Delta \mathrm{R}^{2}=.02\right.$, $\mathrm{F}=8.516, \mathrm{p}<001)$. In the second step of the model, it is seen that self-determination and self-compassion are also meaningful contributions to the model; self-determination and self-compassion together explain $12 \%$ of interpersonal patience. In the third step of the model, it is seen that self-determination and self-compassion together with five factor personality traits were found to have a meaningful contribution to the model; self-determination, self-compassion and personality traits together explain $21 \%$ of the interpersonal patience. Neuroticism $(\beta=-.23, p$ $<.001)$ and agreeableness $(\beta=.22, p<.005)$ where found to be the best predictors for interpersonal patience.

\section{Discussion}

As a result of the study, there was a significant positive correlation between all sub-dimensions of patience and self-compassion. There was a significant relationship between the sub-dimensions of patience and the Self-contact sub-dimension of self-determination. There was a significant positive correlation between the sub-dimensions of patience and agreeableness, openness to experiences and conscientious; and a negative correlation with Neuroticism. There was a significant relationship between Extraversion and patience for difficulties in life as sub-dimensions of patience. İt was seen that when self-compassion, self-determination, and five-factor personality traits were evaluated separately and together, they predicted all the sub-dimensions of patience. The best predictor for patience in everyday life as a sub dimension of patience was the Neuroticism sub dimension of the five-factor personality traits. İt was seen that the best predictor for patience in life difficulties and interpersonal patience was self-compassion.

Table 7. Findings Whether Students Self-Determination, Self-Compassion and Five-Factor Personality Traits Predict İnterpersonal Patience

\begin{tabular}{|c|c|c|c|c|c|c|c|c|c|}
\hline Mode & & $\mathrm{R}$ & $\mathrm{R}^{2}$ & $\Delta \mathrm{R}^{2}$ & $\mathrm{~F}$ & Df & Beta & B & $\mathrm{P}$ \\
\hline & Stable & & & & & & & 6.37 & $.00 * *$ \\
\hline \multirow[t]{3}{*}{1} & Self-contact & $.14 \mathrm{a}$ & .02 & .02 & 8.516 & $2 / 1163$ & .12 & .06 & $.00 * *$ \\
\hline & Choicefulness & & & & & & .14 & .10 & $.00 * *$ \\
\hline & Stable & & & & & & & 1.78 & $.00 * *$ \\
\hline \multirow[t]{2}{*}{2} & Self-Compassion & $.35 b$ & .12 & .12 & 37.734 & 3 & .34 & .06 & $.00 * *$ \\
\hline & Stable & & & & & & & 3.77 & \\
\hline \multirow[t]{5}{*}{3} & Neuroticism & $.46 \mathrm{c}$ & .22 & .21 & 27.293 & $8 / 1158$ & -.23 & -.08 & $.00 * *$ \\
\hline & Extraversion & & & & & & .06 & .01 & .20 \\
\hline & Openess & & & & & & -.08 & -.03 & .07 \\
\hline & Agreeableness & & & & & & .22 & .06 & $.00 * *$ \\
\hline & Conscientious & & & & & & -.06 & -.02 & .13 \\
\hline
\end{tabular}

**p $<.01, * \mathrm{p}<.05$ 
About patience and self-determination: There was a significant positive relationship between the Self-contact sub- dimension of the self-determination scale and the patience points of patience in everyday life, patience in life difficulties and interpersonal patience from the patience scale of university students. On the other hand, there was no positive relationship between the choicefulness sub dimension of the self-determination scale and the patience points of patience in everyday life, patience in life difficulties and interpersonal patience from the patience scale. In addition, it was seen that the Self-contact sub-dimension of the self-determination scale do explain the patience in daily life, patience in life difficulties and interpersonal patience significantly; whereas the choicefulness sub-dimension explained patience in life difficulties and interpersonal patience. This result shows that Self-contact increased as patience level increased. Patience is a concept that includes being able to remain calm and tolerant in face of adverse events (Schnitker, [43]). Individual awareness can be defined as the individual is aware of his/her psychological needs and taking the necessary steps in order to fulfill this needs. Individual awareness also includes the ability of the individual to recognize and control his / her own feelings (Deci \& Ryan, [11]). Since in both concepts there is a concern about the control of emotions, the relation between patience and the Self-contact sub-dimension of self-determination could be emerged from here.

There were no significant relationship found between the choicefulness sub-dimension of self-determination and the patience scores. Choicefulnes is supposed to meet the autonomy needs of the individual. İf a person performs an action "willingly" and "ully approved" these actions, they are considered as autonomous (Ryan \& Deci, [42]). Therefore, the individual feels that he has an initiative on his behavior and becomes the advocate of what he does. Patient individuals calmly wait that the events get corrected, rather to defend them. From this point of view, it can be said that individuals who are not choicefulness, are less autonomous. For this reason, there may be a relationship between the choicefulness sub-dimensions of the self- determination scale and the patience points. Deci \& Ryan [11] thinks that motivation is an innate force a person tries to understand all kinds of phenomena, events and objects he or she has encountered from birth, and is pleased to do so. These feelings and actions are at the root of an individual's achievements. Therefore, there must be a self-regulation for obtaining self-determination. When we look at the literature about patiente it's seen that no studies on self-determination have been conducted, but the studies by Blount \& Janicik [4] on self-regulation are summarized below. Blount $\&$ janicik [4] mentions three mechanisms in understanding the patience behavior: avoidance from obstruction, self-regulation and temporal sacrifice. Whenever individuals feel impatient, they avoid obstructions in order not to encounter a negative result. Temporal sacrifice is the deferment of one's goals by giving priority to them by empowering others to realize their goals. Another important mechanism is self-organization. The concept of self-regulation for patience is seen in tolerance situations. It occurs in situations such as the use of social perceptions of individuals in their goals. Distraction in tolerance situations, focuses on important points. For example; rather than focusing on what the speaker is saying during a conversation, the individual is thinking of that he will be reminded of when the next staff meeting will be held. In other words, they argued that patient individuals are closely related to the self-regulating behavior underlying the concept of self-determination. The findings of Blount \& Janicik [3] are confirming the findings from our study. Another study examining the relationship between self-regulation and patience is the work of Scnitker [45]. He separated patience from self-regulation. He said that patience as a feature is a part of self-regulation. İn Blount \& Janicik [4]'s model, patience is not just a simple attitude towards accountability and appraisal. Patience also has cognitive, behavioral bases. Patient persons are calmer and merciful, impatient individuals are accusatory and nervous. Patient persons can also perform cognitive and behavioral self-regulation. On the other hand, they can easily evaluate and assess the problem situation.

About patience and self-compassion: In this hypothesis of the study, it was tested whether patience and self-compassion are related and the explanation power of patience was tested. As a result of the analysis; there was a positive correlation between the self-compassion of the university students and patience in daily life, patience in life difficulties and interpersonal patience from the patience scale. It was also seen that self- compassion can explain patience in daily life, patience in life difficulties and interpersonal patience in a meaningful way.

According to the results obtained, a positive relationship was found between the patience scores and the selfcompassion score at a .001 significance level. This result shows that the higher the self- compassion level of the individual is the more patient behaviors it displays.

The concept of patience is among the basic attitudes of conscious awareness therapies, which are the foundations of the Buddhist philosophy (Kabat \& Zinn, [26]). These attitudes are classified in 7 categories: Being non-judgmental, Patience, Beginners mind, Trust, Not to be greedy, Acceptance, let things slide (Kabat \& Zinn, [28]).

Patience is a kind of wisdom. Patience is to acknowledge and understand that everything has a time. A child can try to help by opening a crown to a butterfly. Usually this does not help the butterfly; every adult knows that the butterfly comes only out when it is its time, so you should not act hastily in this process. We should treat ourselves as if we were treating butterflies. At some times we need to prefer better times. Each of these times is our present life. Mostly our thoughts affect our perception of the present and lead to the interruption of our connection with the present. To be patient means; to be open to every single moment, accepting it as it 
is, and knowing everything has a time, just as it is in the case of butterflies (Kabat \& Zinn, [28]). Patience therefore stays under the concept of self-compassion, and as self-compassion increases, so does patience.

In other researches where findings which supports our findings. Blount \& Janicik [4] found a moderate correlation between patience and self- compassion. There is also a meaningful relationship between conscious awareness, one of the three basic components of self-understanding. It is necessary to evaluate together with conscious awareness to develop patience (Collard \& Walsh, [9]). Conscious awareness exercises increase creative thinking, memory and patience. In formal practices in awareness therapy, patience and modesty are needed in meditation. Instead of consciously recognizing destructive habits, it is simply aimed at changing with new habits, increasing awareness; but this takes time. Patience in the Blount \& janicik [4] model, is not a simple attitude and includes affective and behavioral responses. That's the reason why patient people are more calm and wise. Impatient people show signs of blame and accusation. Patient persons also rethink the situation and perform self-regulation while giving cognitive and behavioral responses to others' behaviors. A positive relationship was found between patient persons and compassion and calm $(\mathrm{p}<.001)$. When Blount \& Janicik[ 3] were observing persons waiting at the airport to assess the affective and cognitive responses of them for their study, they found a significant relationship between threats, challenges, blaming airways and accusing air conditions. It has been seen that the waiting reactions of patient people are more reasonable. Blount \& janicik [4] pointed out that in delayed situations persons made causal attributions for "any object, person, fate, luck, or gods" and in situations where the delays have to be tolerated it has been seen that patient persons are more compassionate than impatient persons.

About Patience and the Five Factor Personality Traits; in this hypothesis of the study, the ability of the patience scores to explain five factorial personality traits of individuals' was tested. As a result of the analysis, patience was found to explain the five-factor personality traits at a significant level.

When the findings were examined, the five factor personality trait was found to be able to explain significantly $21 \%$ of the patience in daily life, $21 \%$ of patience in life difficulties, and $21 \%$ of interpersonal patience. Therefore, it is possible to predict the levels of patience by looking at the personality traits of individuals. When we look at the relationship between self-compassion and personality, there was a positive relationship between patience scores and to be open for experiences, agreeableness and conscientious and a negative relation with neuroticism. There was no significant relationship between the Extraversion scores.

Between the patience in life difficulties and Extraversion, Openness, Conscientious scores there was found a significant positive relationship and a significant negatively relation with Neuroticism. Between the interpersonal patience scores and Extraversion, Openness, conscientious scores there was found a significant positive relationship and a significant negatively relation with Neuroticism. According to these results, patient individuals are compatible, responsible, open and outgoing. When we look at the regression between large five-personality and three-factor patience, it seems that patience is an important predictor of the big five in the three dimensions of patience (patience in everyday life, patience in life difficulties and interpersonal patience). It has been found that there is a negative relationship between the five-factor personality theory and the Neuroticism dimension. Patient individuals can calmly wait and worry less about adverse situations. It is seen that individuals which have the neuroticism dimension of the five factorial personality theory, show less emotional stability and personal adaptation continuity. People who were experiencing emotional distress and who showed extreme changes in their emotions received a high score in terms of neuroticism (Burger, [6] ). At this point, as the level of patience of the individual increases, then neuroticism decreases. There was no significant relationship between the patience in everyday life sub-dimension of patience and interpersonal patience and Extraversion. For patience in life difficulties, a moderate relationship was found in the patience dimension. Outgoing individuals are highly social; at the same time energetic, optimistic, warm-hearted, sociable and enterprising. Outgoing individuals are in a hurry to express their feelings immediately. Patient individuals expect to be more calm and confident. Therefore, there may be no relationship between them or just a moderate relationship. In the field literature, two studies on five factorial personality traits and patience are striking. Schnitker and Emmons [44] found a high positive correlation between patience and compatibility, conscientious, extroversion, and experiential openness in their study about patience and five-factor personality theory; and they found a negative relation with neuroticism. Schnitker [45] may contribute to patience in determining the relationship between patience and various personality variables. The time perception of the waiting person is an important determinant. Positive and negative experiences in the past affect the ability of the future of individuals to give patient reactions in response to events. Those who perceive the past and the future as positively, tend to be more patient in 'the living moment" or now. Individuals, who have a negative perception of time in the past, tend to be less patient or impatient. Patient individuals focus on positive rather than negative when they plan the future or think about the past, and enjoy the moment. About 20 'relationships were found between the various factors of patience and the characteristics of the big five personality, and there was a moderate positive correlation between patience in life difficulties and patience in everyday life and compatibility. There was a strong positive correlation between interpersonal patience and compatibility among individuals. There was a negative relationship between conscientious and neuroticism in three factor patience scale. There was found 
moderate correlations between interpersonal patience and openness to experiences, and a positive moderate correlation between long-term and short-term patience and openness to experiences. Finally, the relationship between Extraversion and patience types is not statistically significant (Schnitker \& Emmons, [44]). According to these results, patient individuals are compatible, responsible and open. They may or may not be open to the outside in negative emotions. When we look at the regression between the big five and the three-factor patience, it seems that patience is an important determinant of the big five. There was a positive moderate relationship between compatibility and Neuroticism and a positive one conscientious and openness for experiences. There was no relationship found between Extraversion and patience. In his second study, Schnitker [43] evaluated patience and five factor personality traits and found that three dimensions of patience and five-factor personality traits were associated with compliance, conscientious, neuroticism and openness to experiences dimensions. There was a strong relationship between interpersonal patience and compatibility, and a moderate relation between patience in life difficulties and with patience in everyday life. İnterpersonal patience was an important predictor of all factors of the five-factor personality traits. İnterpersonal patience predicted compatibility in a strong way and had a moderate relationship with neuroticism. These results are supporting our research.

The limitations and results of the study are as follows:

1. The data of the study is limited to the students of Konya Necmettin Erbakan University, Batman University and Bartın University.

2. The data of the study is limited to the measured qualifications of the "Personal Information Form", Self-compassion Scale, Patient Scale and Adjective-Based Personality Test (SDKT).

3. The findings of the study are limited to the findings obtained from students of Konya Necmettin Erbakan University, Batman University and Bartın University.

4. A positive significant relationship was found between all sub-dimensions of patience and self-compassion. There was a significant relationship between the sub-dimensions of patience and the individual awareness sub-dimension of self-determination. There was a significant positive correlation between the sub-dimensions of patience with agreeableness, openness and conscientious; also a significant negative correlation with neuroticism. There was a significant relationship between extraversion and the patience in life difficulties sub-dimension of patience.

5. It is seen that self-compassion, self-determination and five-factor personality traits did predict all sub-dimensions of patience when assessed separately and together. The best predictor for the patience in everyday life sub-dimension of patience was the neuroticism sub-dimension of the five-factorial personality traits. The best predictor for patience in everyday life and interpersonal patience was the neuroticism sub-dimension of the five-factorial personality traits.

Based on the findings of the study, the following suggestions can be developed:

1. The finding that there is a relationship between individuals' patience scores and self-compassion, self-determination and personality traits and that it has an influence; indicates that individual and group psychological counseling and guidance practices for improving patience and self-compassion, will also improve the patience levels of university students. This recommendation is especially important for psychological counseling centers of universities and for psychological counselors who are working with young adults.

2. A seminar on personality development for parents, children and adolescents can be organized when the influence of personality traits on individuals' patience levels is taken into account.

3. It is thought that the practices carried out in order to develop the individuals patience in life difficulties, patience in everyday life and interpersonal patience and to improve their patience levels in general; will have a positive contribution to the lives of the individuals and will cause their change and personal development.

4. The current study is the first in our country which includes patience and the patience scale adapted to Turkish may contribute to further research.

5. Introducing practices to the guidance programs in schools by psychological counselors to the psychiatric counseling and guidance field in order to improve patience and self-compassion, may be beneficial for students in developing these skills.

\section{REFERENCES}

[1] Allport, G. W. (1937). Personality: Psychological Interpretation. Holt, Rinehart and Winston: New York.

[2] Bacanlı H, İlhan T, Aslan S. (2009) Beş faktör kuramına dayalı bir kişilik ölçeğinin geliştirilmesi: Sıfatlara dayalı kişilik testi (SDTK). Türk Eğitim Bilimleri Dergisi; 7 (2), 261-279.

[3] Blount, S. \& Janicik, G. A. (1999). Comparing social accounts of patience and impatience. Unpublished manuscript, University of Chicago.

[4] Blount, S. \& Janicik, G. A. (2000). What makes us patient? The role of emotion in sociotemporal evaluation. Unpublished manuscript: University of Chicago.

[5] Blount, S. (1995). When social outcomes aren't fair: The effect of causal attributions on preferences. Organizational Behavior and Human Decision Processes, 63 (2), 131-144.

[6] Burger, J. M. (2006). Kişilik. (1.Bask1). İstanbul: Kaktüs Yayınlar1. 
[7] Carver, C. S., Scheier, M. F. \& Weintraub, J. K. (1989). Assessing coping strategies: A theoretically based approach. Journal of Personality and Social Psychology, 56(2), 267-283.

[8] Cebecioğlu, E. (2005). Tasavvuf Terimleri ve Deyimleri Sözlüğü. İstanbul. Anka yayınları.

[9] Collard, P., \& Walsh, J. (2008). Sensory awareness mindfulness training in coaching:Accepting life's challenges. Journal of Rational - Emotive \& Cognitive - Behavior Therapy 26(1), 30-37.

[10] Curry O. S., Price M.E. \& Price J.G. (2008). Patience is a virtue: Cooperative people have lowe discount rates Personality and Individual Differences, 44(3), 780-785.

[11] Deci, E. L. \& Ryan, R. M. (1985a). Intrinsic motivation and self-determination in human behavior. New York, NY: Plenum Press.

[12] Deci, E. L. \& Ryan, R. M. (1985b). Intrinsic Motivation and Self-Determination in Human Behavior. New York: Plenum.

[13] Deci, E. L., Connell, J. P. \& Ryan, R. M. (1989). Self-determination in a work organization. Journal of Applied Psychology, 74 (4), 580-590.

[14] Deci, E. L., \& Ryan, R. M. (2000). The 'what' and 'why' of goal pursuits: Human needs and the self - determination of behaviour. Psychological Inquiry, 11, 227 - 268.

[15] Deniz, M. Engin., Kesici S. \& Sümer S. (2008). The Validity and Reliability Study of the Turkish Version of Self-Compassion Scale. An International Journal of Social Behavior and Personality, 36 (9), 1151-1160.

[16] Dudley, K. C. (2003). Empirical development of a scale of patience. Dissertation Abstracts International, 54 (8), 4332

[17] Ericson, E.H. (1984). İnsanın sekiz çağı (Çev. Bedirhan Üstün $\&$ Vedat Şar) Birey ve Toplum: Ankara.

[18] Freud, S. (1920). Beyond the pleasure principle. SE, 18: 1-64.

[19] Gilbert, P. (2000). Social mentalities: Internal "social" conflicts and the role of inner warmth and compassion in cognitive therapy. In P. Gilbert, ve K. G. Bailey (Eds.), Genes on the couch: Explorations in evolutionary psychotherapy. Hove: Brunner Routledge.

[20] Goss, K. \& Gilbert, P. (2002). Eating disorders, shame and pride: A cognitive behavioural functional analysis. In P. Gilbert, \& J. Miles (Eds.), Body shame: Conceptualisation, research and treatment. Hove, UK: Brunner- Routledge.

[21] Hayes, S. C. (2004). Acceptance and commitment therapy, relational frame theory, and the third wave of behavior therapy. Behavior Therapy, 35(4), 639-665.

[22] Hofmann, S. G. \& Asmundson, G. J. (2008). Acceptance and mindfulness-based therapy: New wave or old hat? Clinical Psychology Review, 28(1), 1-16.

[23] Hofmann, S. G., Sawyer, A. T., Witt, A. A., \& Oh, D. (2010). The effect of mindfulness-based therapy on anxiety and depression: A meta-analytic review. Journal of Consulting and Clinical Psychology, 78(2), 169-183.

[24] Hursthouse, R., (1999). Virtue Ethics and Human Nature, Hume Studies Volume XXV, Number 1 (2), 67-82.
[25] Jung, C. (1992).Two Essays on Analytical Psychology, London: Routledge.

[26] Kabat-Zinn, J. (1982). An outpatient programin behavioral medicine for chronic pain patients based on the practice of mindfulness meditation. General Hospital Psychiatry, 4, 3347.

[27] Kabat-Zinn, J. (1994). Wherever you go there you are. New York, NY: Hyperion

[28] Kabat-Zinn, J. (2005). Coming to our senses: Healing ourselves and the world through mindfulness. New York, NY: Hyperion

[29] Kasser, V. G., \& Ryan, R. M. (1999). The Relation of Psychological Needs for Autonomy and Relatedness to Vitality, Weil-Being, and Mortality in a Nursing Home. Journal of Applied Social Psychology, 29 (5), 935-954.

[30] Kowal, J., \& Fortier, M. S. (1999). Motivational determinants of flow: contributions from self-determination theory. The Journal of Social Pscyhology, 139(3), 355

[31] Krapp, A. (2002). Structural and dynamic aspects of interest development: theoretical considerations from an ontogenetic perspective, Learning and Instruction, 12, 383- 409.

[32] McCullough, M. E., Tsang, J., \& Emmons, R. A. (2004). Gratitude in intermediate affective terrain: Links of grateful moods to individual differences and daily emotional experience. Journal of Personality and Social Psychology, 86(2), 295-309.

[33] Mehrabian, A. (1999). Manual for the Revised Achieving Tendency (MACH) and Disciplined Goal Orientation (CGO) Scales. Monterey, California: Alta Mesa

[34] Neff, K. D. (2003a). Development and validation of a scale to measure self-compassion. Self and Identity, 2, 223-250.

[35] Neff, K. D. (2003b). Self-compassion: An alternative conceptualization of a healthy attitude toward oneself. Self and Identity, 2, 85-101.

[36] Noels, K. A., Pelletier, L. G., Clément, R. \& Vallerand, R. J. (2000). Why are you learning a second language? Motivational orientations and self-determination theory. Language Learning, 50 (1), 57-85.

[37] Poulsen, Anne A., Rodger, Sylvia \& Ziviani, Jenny M., (2006). "Understanding children's motivation from a self-determination theoretical perspective: implications for practice", Australian Occupational Therapy Journal, 56 (2), 78-86.

[38] Roemer, L. \& Orsillo, S. M. (2009). Mindfulness- ve acceptance-based behavioral therapies in practice. New York, NY: Guilford.

[39] Rogers, C. R. (1980). A way of being. Boston: Houghton Mifflin.

[40] Ryan, R. M. \& Brown, K. W. (2003). Why we don't need self-esteem: Basic needs, mindfulness, and the authentic self. Psychological Inquiry, 14,(1) 71- 76.

[41] Ryan, R.M. \& Deci, E.L. (2000). Self-Determination Theory and the Facilitation of Intrinsic Motivation, Social Development, and Well-Being. American Psychologist, 55(1), 68-78. 
[42] Ryan, R. M. (2009). Self-determination theory and wellbeing. California,Wellbeing Developing Countries- Wed Research Review 1.

[43] Schnitker S. A. (2012). An examination of patience and well-being, The Journal of Positive Psychology: Dedicated to furthering research and promoting good practice, 7(4), 263-280

[44] Schnitker, S. A. \& Emmons, R.A. (2007). Patience as a virtue: Religious and psychological perspectives. Research in the Social Scientific Study of Religion, 18, 177-207

[45] Schnitker, S.A. (2010). Does the virtue of patience promote well-being? Efficacy of a patience training program and evidence from dynamic longitudinal analyses of goal striving. University of California Dissertation

[46] Sheldon, K. \& Deci, E. (1996). The Self Determination Scale, Unpublished manuscript, University of Rocchester.

[47] Sheldon, K.M., Ryan, R.M., Deci, E.L. \& Kasser, T. (1996). The independent effects of goal contents and motives on well-being: It's both what you pursue and why you pursue it. Personality and Social Psychology Bulletin, 30(4), 475-486.

[48] Siegel, D. (2007). The mindful brain: Reflections on attunement in the cultivation of well-being. New York, NY: Norton.

[49] Somer, O. (1998). Türkçe'de kisilik özelliği tanımlayan sıfatların yapısı ve besfaktör modeli. Türk Psikoloji Dergisi, 13(4), 17-312.

[50] Thera, N. (1962). The heart of Buddhist meditation. York Beach, Maine: Weiser.

[51] Uday S. \& Mehta (2011). Patience, 1nwardness, and Self-knowledge İn gandhi's Hind swaraj Public culture, Copyright duke university press, 23(2) 240

[52] Whetten, D. \& K.Cameron (1995). Developing Management Skills. Newyork, Guilford press.

[53] ELİ̈ŞÜK, A, Arslan, C. "Sabır Ölçeğinin Türkçe'ye Uyarlanması: Geçerlilik ve Güvenirlik Çalışmaları". Değerler Eğitimi Dergisi 14 (2016): 67-86 